\title{
The Paper River: A Demonstration of Externalities and Coase's Theorem
}

\author{
Gail M. Hoyt, Patricia L. Ryan, \\ and Robert G. Houston, Jr.
}

\begin{abstract}
It is necessary to know whether the damaging business is liable or not for damage caused since without the establishment of this initial delimitation of rights there can be no market transactions to transfer and recombine them. But the ultimate result (which maximises the value of production) is independent of the legal position if the pricing system is assumed to work without cost.
\end{abstract}

R. H. Coase

The Paper River is a classroom simulation designed to examine a negative externality generated by a productive process that elicits a Coasian solution. Previous experiments designed by Hazlett (1995), Nugent (1993, 1997), and Bergstrom and Miller (1997, 179-99) focus on how pollution emission rights can be efficiently allocated by the market through property rights. Although these experiments touch on property rights in demonstrating how emission rights are a more efficient means of reducing pollution than government imposed limits, they do not address Coase's Theorem directly. Classroom experiments that demonstrate Coase's Theorem include those by Delemeester and Neral (1995, 115-19) and Stodder (1996). In these activities, students imagine they are either the creator or recipient of a hypothetical externality. Although this approach is useful for conveying Coase's Theorem, it does not give students the opportunity to generate and experience the externality directly. In the Paper River, students create and experience an externality first hand and then conceptualize a correction procedure that is consistent with Coase's Theorem. The unique nature of this simulation allows students to be involved directly in the externality. In addition, it simulates an actual environmental problem, which will enable students to identify more easily other examples of externalities that affect our society, such as endangered species, destruction of the rainforests, and preservation of natural habitats.

\section{OVERVIEW}

This activity simulates two firms located along a river in which one firm pollutes the water used by another firm downstream. The river water is represented

Gail M. Hoyt is an associate professor of economics at the University of Kentucky (e-mail: GHOYT@POP.UKY.edu).Patricia L.Ryan is an assistant professor at Midway College and a doctoral candidate at The University of Kentucky, as is Robert G. Houston, Jr. The authors thank the following individuals for their assistance in developing and testing the activities:M. Berger, G. Blomquist, S. Dickert-Conlin,R. Gift, W. Hoyt, F. Scott,and microeconomics principles teaching assistants at the University of Kentucky as well as the anonymous referees for their insightful comments. 
by small sheets of paper that are given to the Firm A students (upstream firm) who use them to generate answers to math problems. The used paper is then passed to the Firm B students (downstream firm) who must clean up the "pollution" before using the paper to produce paper airplanes. Once students experience firsthand how an external cost arises, they are given the opportunity to determine how to correct the market failure. In the process, students gain an understanding of Coase's Theorem and learn how the market can internalize these costs through assigning property rights. This activity has been tested over several semesters by numerous instructors and has been refined according to the instructors'comments to insure successful implementation. Minimal preparation and class time are required.

\section{Preparation}

To begin, the instructor will need the following:

- Fifteen minutes of preparation time

- Thirty minutes of class time

- Twenty multiplication problems

- One record sheet for every two students

- One sheet of $8 \frac{1}{2} \times 11$ inch paper for every two students

- One pencil with eraser for each student

The instructor writes 20 three-digit by two-digit multiplication problems (e.g., $376 \times 92=\ldots$ ), creating two sets of 10 problems that are written on the board during class. A sample record sheet the students use to record their earnings is given in Figure 1. There should be one copy for every two students. To create the small pieces of paper used during the simulation, a standard size piece of paper should be cut in half lengthwise. The resulting halves are then cut into five equal rectangles, so that the paper is divided into 10 equal pieces (Figure 2). Enough pieces should be made so that half the students receive 10 small pieces of paper. ${ }^{1}$

\section{Procedure}

The instructor selects a student assistant a few minutes before class starts and shows him/her how to make a paper airplane using one of the small pieces of paper you have prepared. The classroom simulation requires an even number of participants. Therefore, if an odd number of students are present, the assistant will not participate. If an even number of students is present, the assistant will participate as a Firm B student.

\section{ROUND ONE}

When it is time to conduct the simulation, the instructor should make sure that each student has a pencil with an eraser and say to the class, "Clear your desks except for a pencil. Each person on the right side of the room represents Firm A, and each person on the left side of the room represents Firm B." The instructor 


\section{FIGURE 1 \\ Record Sheet (Sample)}

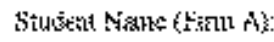

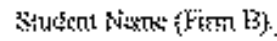

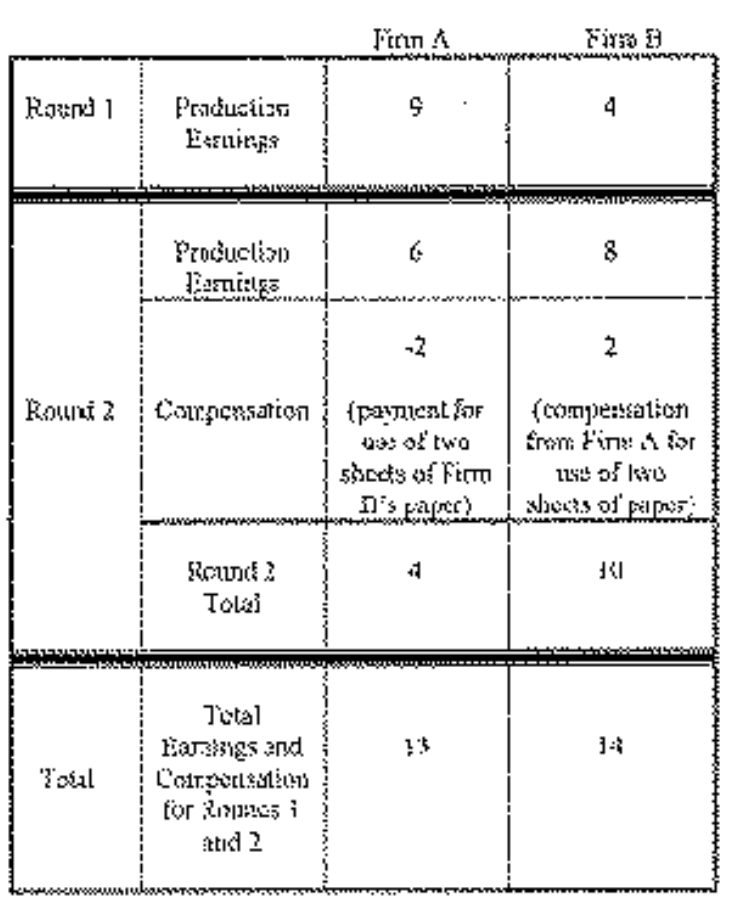

should have the student assistant give five pieces of paper and a record sheet to each Firm A student. While these are being distributed, the instructor writes the first set of 10 multiplication problems on the board and offers a reward to the Firm A students for producing answers to these problems. We use bonus points; however, any type of reward can be used as long as it provides a sufficient incentive and is transferable between students. Firm A students should be given an incentive to produce answers to the math problems by the instructor saying, "Firm A students will receive one bonus point for each math problem answered correctly. You have three minutes to produce these answers using any resources that are readily available, which includes the pieces of paper that were distributed and a pencil." Calculators and other scratch paper have been removed; therefore, these resources cannot be used.

While the Firm A students are working furiously on math problems, the student assistant quietly shows the Firm B students how to make paper airplanes. The Firm A students will complete the math problems using the blank pieces of 
FIGURE 2

Paper Division for Simulation

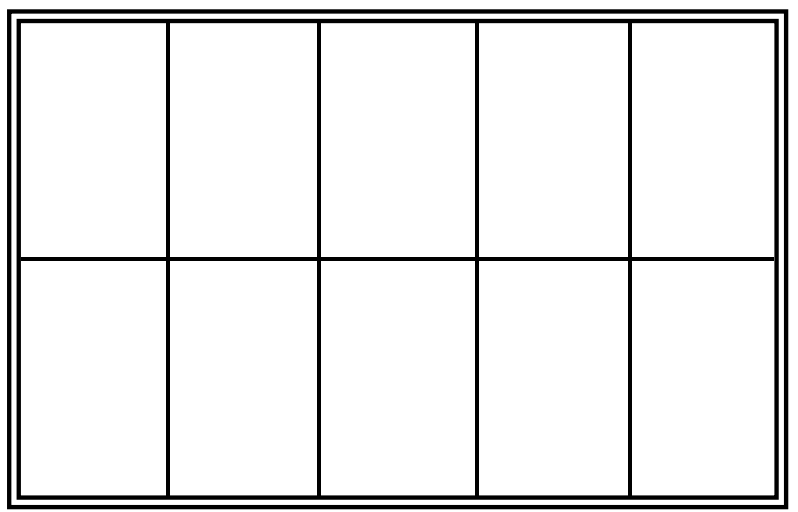

paper they were given. Many of the students will use one sheet for each problem; some will use both the front and the back of the paper to produce two problems per sheet of paper. A few students may write very small in order to squeeze several calculations onto one sheet. However, if the profit motive is strong enough, the students will not go to this extra effort. When time is up, the instructor gives the correct answers to the problems and says to the Firm A students, "Check your answers and record your earnings on your record sheet. Then, give your five pieces of paper and record sheet to a Firm B student."

Once the Firm B students have the pieces of paper, they should receive the following instructions: "You will receive two bonus points for each paper airplane you can produce in three minutes using the paper that was just given to you from Firm A. If you wish to use your own airplane design, you will get paid as long as it is the required size, can fly, and has no writing on it. You are allowed to com pletely erase pencil marks, but you are not allowed to tear off portions of the paper to remove pencil marks."

Some Firm B students will not have any clean paper to use and others will run out quickly. This will cause many students to spend valuable time erasing. These students will be very unhappy because Firm A has prevented them from earning bonus points. An alternative way to look at it is that Firm A did not consider the full cost of its actions; it ignored external cost. When the three minutes have passed, the instructor says to the Firm B students, "Record your earnings based on the number of acceptable airplanes you have produced." The instructor should take note of the Firm B students who were most affected by the externality and ask some of them, "How much of a cost was imposed on you in terms of the number of bonus points you were prevented from earning?"

At this point in the exercise, the instructor explains how the simulation is rep- 
resentative of a common problem that exists in our society. He or she draws two firms on the board along a river with Firm B downstream from Firm A and explains the nature of the externality. A possible explanation might be:

Firm B uses the water from the river in a filtering process to manufacture its product, however, Firm A is currently dumping waste into the river. Because of Firm A's dumping, Firm B must pay to purify the water before it can be used. Thus, Firm A has imposed an external cost on Firm B. Firm B values the pieces of paper, which represent the river. Because Firm B has no control over how this resource is used, Firm A inefficiently over-utilizes it to produce answers to math problems. Firm B can choose to erase the pencil marks (cleaning up the pollution) or simply suffer the loss of that particular resource. Because of the lack of property rights, Firm A will tend to overproduce its product because it is only considering its own costs, not those that it imposes on Firm B.

After the explanation of the externality, and prior to the explanation of Coase's Theorem, the instructor trys to elicit a Coasian solution from students. A line of questioning similar to the following is suggested to accomplish this objective:

- What could be changed in order to make Firm A take into account not only its costs but also the costs it is imposing on Firm B?

- How much did Firm A have to pay to use the paper?

- How does the lack of a private cost to Firm A for using the paper influence its decision regarding paper utilization?

- How could society insure that a firm takes into account not only its private costs, but also the social costs of production?

- Should Firm A pay? Should Firm B pay? How should it pay? Who should it pay?

In response to this discussion, students typically assign the property rights to Firm B by suggesting that Firm A pay Firm B one or two bonus points for each piece of paper that has been used in order to compensate them for the lost resource. Occasionally, students will grant the property rights to Firm A by suggesting that Firm B pay to get the blank pieces of paper from Firm A. However, it should be noted that to make a profit Firm B would have to pay a price lower than two bonus points per sheet. Regardless, Firm A will now have an incentive to use the paper more efficiently and as a result will conserve the resource. On the basis of class discussion, choose a payment scheme that grants the property rights to either Firm A or Firm B. This will mark the end of round one. In the remainder of this article, we will assume that Firm A must pay Firm B one bonus point for each piece of paper used, thus assigning the property rights to Firm B.

\section{ROUND TWO}

The entire simulation is repeated, but now the payment scheme chosen at the end of round one is incorporated. After collecting all of the old paper and returning the record sheets to the Firm A students, the assistant passes out five new pieces of paper to each Firm A student, and the exercise is repeated using the second set of math problems. While Firm A students are producing answers to 
the math problems, the instructor walks around the room to see how different students are responding to the new incentive structure. He or she should mentally select a few students to call upon later to explain how the new incentive structure altered their production process. These students will be useful when demonstrating how changing the cost to Firm A provided an incentive that resulted in an effort to conserve the paper because it is now valued by the firm.

Some things to look for are:

- Individuals who do all of their work on one piece of paper, and as a result their production declines considerably.

- Individuals who choose to use two or three pieces of paper, without a significant decline in their production.

- Individuals who choose to produce answers without the use of paper, illustrating a firm choosing an alternative production method.

- Individuals who choose not to produce at all.

Once the three minutes have passed, the instructor calls on the students he or she has mentally selected and asks each student, "How many problems were you able to solve in the first production round versus the second production round? Did you change how you used your paper and did this affect your output?" Most students will have decreased their efforts (illustrating a reduction in output), and all will have changed their production process to conserve the valued resource because they have now internalized the cost of their actions.

Each of the Firm A students should record their earnings and compensation for using Firm B's resource (Figure 1). Firm A students should then give the paper and record sheet to the Firm B students. The Firm B students should have three minutes to produce airplanes. Once time is called, Firm B students should record their earnings and compensation from Firm A. At the end of round two, the instructor summarizes the simulation.

In this economy where answers to math problems and paper airplanes are produced, there is an efficient production of the two goods now that Firm A is considering the cost of the resource it is using. Before, larger quantities of math answers were produced at the expense of paper airplanes. The existence of the externality caused math answers to be overproduced and led to the underproduction of paper airplanes. Once the externality is corrected, resources will be allocated more efficiently so that neither good is over- or underproduced. You will also note that this solution is more efficient as the total number of bonus points earned by Firms A and B combined increases because of an overall increase in production.

Coase's Theorem should be illustrated at this point by explaining that regardless of which firm receives the property rights, the externality is internalized. For instance, the instructor can ask the class the following question, "Would the outcome of the last round have changed if Firm B had bought the pieces of paper from Firm A?" Because Firm A knows it will be able to sell unused pieces of paper to Firm B, it will tend to conserve the resource just as it did when Firm A had to pay for using the resource. One could use Coase's example of the farmer and rancher to further illustrate that regardless of which party is granted the property rights, the problem is corrected assuming transaction costs are sufficiently low (Coase 1960). ${ }^{2}$ 
The instructor can conclude the simulation by discussing the income effects of assigning property rights and how a Coasian solution could be prevented by high transaction costs. A natural extension of this discussion could include the use of a Pigouvian excise tax to correct a negative externality. One could discuss with the class whether the last simulation would have changed if Firm A had paid the instructor (the government) instead of Firm B.

\section{NOTES}

1. The size of the paper is key to a successful simulation. If the pieces of paper are too large or too small, it could affect the results. This size has been used numerous times in many different classes and has been found to work very well.

2. Students often perceive the two parties involved in an externality as villain and victim. It should be made clear to them that without the presence of both parties, the externality would not exist. If only Firm A or only Firm B is located along the river, no externality exists between the firms.

\section{REFERENCES}

Bergstrom, T. C.,and J. H. Miller. 1997. Experiments with economic principles. New York:McGrawHill.

Coase, R. H. 1960. The problem of social cost. Journal of Law and Economics 3 (October):1-44.

Delemeester, G., and J. Neral. 1995. Classroom experiments: To accompany Taylor's economics: A user's guide. Boston: Houghton Mifflin.

Hazlett, D. 1995. An EPA-style auction of pollution permits. Classroom Expernomics 4 (1): 3-7.

Nugent, R. 1993. Pollution rights trading game. Classroom Expernomics 2 (2): 3_5.

. 1997. A pollution rights trading game. Economic Inquiry 35 (3): 679-85.

Stodder, J. 1996. An experiment on externality rights. Classroom Expernomics 5 (1): 5-7. 